\title{
Risk factors for melanoma and skin health behaviour: An analysis on Romanian melanoma patients
}

\author{
OANA FECHETE ${ }^{1}$, LOREDANA UNGUREANU ${ }^{1}$, SIMONA ȘENIL $\breve{~}^{1}$, DANIELA VORNICESCU ${ }^{1}$, \\ SORINA DĂNESCU ${ }^{1}$, ALINA VASILOVICI ${ }^{1}$, ELISABETA CANDREA ${ }^{1}$, \\ STTEFAN CRISTIAN VESA ${ }^{2}$ and RODICA COSGAREA ${ }^{1}$ \\ Departments of ${ }^{1}$ Dermatology and ${ }^{2}$ Pharmacology, Toxicology and Clinical Pharmacology, \\ 'Iuliu Hațieganu' University of Medicine and Pharmacy, 400000 Cluj-Napoca, Romania
}

Received July 3, 2018; Accepted August 23, 2018

DOI: $10.3892 / 01.2018 .9737$

\begin{abstract}
In contrast to Western Europe, in Central and Eastern Europe reports show higher rates of advanced melanoma and lower survival. Our aim was to document and compare melanoma risk factors and skin health behaviour in patients diagnosed with melanoma and people not affected by this disease in a large medical university centre from Romania (Cluj-Napoca). Two hundred and forty-seven melanoma patients followed-up in the Department of Dermatology at the Cluj-Napoca Emergency County Hospital and 956 people not affected by melanoma completed a paper-based questionnaire regarding melanoma risk factors, risk behaviour and selfprotecting measures, after giving informed consent. People with melanoma had significantly higher personal risk and protective behaviour, and lower risk behaviour than those not affected. Although our data suggest that melanoma patients are better educated about how to avoid a second primary melanoma, our results are concerning when compared with studies from other countries. The low incidence of self and clinical skin-examination together with the relatively low percentage of participants which would consult a doctor in the case of new/changing mole could be one of the explanations for the late diagnosis of melanoma in the studied population. According to our findings, there is an urgent need for population health campaigns regarding not only primary but also secondary melanoma prevention.
\end{abstract}

\section{Introduction}

Although cutaneous melanoma represents only $10 \%$ of the total cutaneous malignant tumours, melanoma is responsible

Correspondence to: Dr Loredana Ungureanu, Department of Dermatology, 'Iuliu Hațieganu' University of Medicine and Pharmacy, 3-6 Clinicilor Street, 400000 Cluj-Napoca, Romania E-mail: danaszent@yahoo.com

Key words: melanoma, risk factors, risk behaviours, protective behaviours, skin-examintion for over $90 \%$ of the deaths caused by these tumours (1). The prognosis is, however, good if it is diagnosed early, before the metastatic stage (2).

Numerous studies have documented increases of melanoma incidence throughout Europe in the last few decades (3). Reports have indicated plateaus and decreases of incidence among young age groups in several Western European and Nordic countries, along with a marked shift towards earlier diagnosis of melanoma throughout Western Europe (3). In contrast, countries from Central and Eastern Europe report higher rates of advanced tumours and lower survival (3). For example, in Bulgaria and Romania, an estimated 25\% of patients present with stage III and IV disease, while thin melanomas under $1 \mathrm{~mm}$ thick comprise less than $10 \%$ of newly-diagnosed cases (3). This is in sharp contrast to Western Europe, where up to $70 \%$ of newly-diagnosed melanomas are $<1 \mathrm{~mm}$ thick and account for most of the increase in incidence (3). Later diagnosis of advanced stage melanoma in Central and Eastern Europe compared with other parts of Europe may partly be accounted for by differences in general educational status, reduced government expenditures for education and lack of specific health education, resulting in lower awareness among the general population and physicians (3).

Studies regarding melanoma knowledge, perception and awareness of risk factors were conducted in Western Europe but only a few studies are available in Central and Eastern Europe (2-11). Moreover, it is unknown whether patients who have been diagnosed with melanoma know more about risk factors and have a different protective behaviour than people who have never had melanoma.

The aim of the present study was to document and compare melanoma risk factors and skin health behaviour in patients diagnosed with melanoma and people not affected by this disease in a large medical university centre in Romania to contribute to the design of future preventive campaigns.

\section{Materials and methods}

Setting. This analytical, observational, transversal, cohort study was carried out in Cluj county, in the North-Western Region of Romania. 
Participants. Between December 1, 2014 and February 28, 2015, all (956) adult patients (18-64 years), presenting to an occupational medicine centre for their annual routine check were invited to complete a paper-based questionnaire regarding melanoma knowledge, risk factors and protective behaviour (11). Respondents gave their implicit consent by completing the questionnaire. The study was approved by the Ethics Committee of the Iuliu Hatieganu University of Medicine and Pharmacy (Cluj-Napoca, Romania). In 2017, we sought to compare a part of the gathered data with data collected from 247 patients diagnosed with melanoma and followed-up in the Department of Dermatology, Emergency County Hospital (Cluj-Napoca, Romania). Not all the participants answered all the questions, so we calculated the percentages considering as $100 \%$ the number of patients who responded.

Study questionnaire. The questionnaire used in this study was adapted from a questionnaire used by Murchie and Iweuke to assess melanoma knowledge and protective behaviour (4). Permission was received to adapt and use the questionnaire. The first questions gathered data on demographics (sex, age and educational level). To aid analysis participants were split into categories depending on their age (18-24, 25-44 and 45-64 years). The remaining questions collected data on the following:

Self-reported melanoma risk factors. The studied population was questioned regarding personal risk factors for melanoma development, including fair skin, presence of nevi or atypical nevi (defined as nevi with irregular margins and colour), red or blond hair and appearance of freckles after sun exposure.

Self-reported risk behaviour. Respondents were asked whether they are exposed to sun during professional activities or vacations, whether they had sunburns and whether they use sunbeds.

Self-reported protective behaviour. The responders were asked whether they usually use sunscreens, whether they consulted a doctor for their moles during the previous year and if they check their skin surface for new or changing moles.

Attitude towards a new or changing mole. The responders were asked what they would do in the presence of a new or changing mole and when they consider a new or changing mole should be checked. In the melanoma group, we added a question regarding the time interval between noticing the tumour and first presentation to the doctor. Paper questionnaires were coded manually and entered into a database.

Statistical analysis. Statistical analysis was performed with MedCalc Statistical Software, version 15.6.1 (MedCalc Software bvba, Ostend, Belgium; https://www.medcalc.org). Nominal variables were described by frequency and percent. Differences between nominal variables were assessed by Chi-square test. $\mathrm{P}<0.05$ was considered to indicate a statistically significant difference.

\section{Results}

Patients characteristics. Two hundred and forty-seven people diagnosed with cutaneous melanoma completed the questionnaire. The studied population comprised 114 (46.2\%) male
Table I. The demographic characteristics of the study population.

\begin{tabular}{lccc}
\hline Variables & $\begin{array}{c}\text { Control } \\
(\mathrm{n}, \%)\end{array}$ & $\begin{array}{c}\text { Melanoma } \\
(\mathrm{n}, \%)\end{array}$ & P-value \\
\hline $\begin{array}{l}\text { Sex } \\
\text { Male }\end{array}$ & $367(38.4)$ & $114(46.2)$ & $>0.01$ \\
Female & $589(61.6)$ & $133(53.8)$ & \\
Age (years $)$ & & & \\
$18-24$ & $165(17.3)$ & $6(2.4)$ & $<0.01$ \\
$25-44$ & $556(58.2)$ & $75(30.4)$ & \\
$45-64$ & $235(24.6)$ & $124(50.2)$ & \\
$<64$ & $0(0.0)$ & $42(17.0)$ & \\
Educational level & & & $<0.01$ \\
Primary school & $102(10.7)$ & $41(19.2)$ & \\
High school & $365(38.2)$ & $71(33.2)$ & \\
Graduate & $383(40.1)$ & $87(40.7)$ & \\
Postgraduate & $106(11.1)$ & $15(7.0)$ & \\
\hline
\end{tabular}

and $133(53.8 \%)$ female. The control group consisted of 956 people, 367 (38.4\%) male and 589 (61.6\%) female. The demographic characteristics of the study population are presented in Table I. We observed a statistically significant difference between the two groups regarding age, eldery individuals being more frequent in the melanoma group compared with the control one. Regarding educational level, the melanoma group comprised more individuals with a primary school level compared with the control group.

Self-reported melanoma risk factors. Self-reported melanoma risk factors in the melanoma and control group are presented in Table II. Melanoma patients were significantly more likely to have fair skin, more than 20 nevi and atypical nevi and more likely to develop freckles after sun exposure than controls.

Self-reported risk behaviour. Self-reported risk behaviour in the two groups is presented in Table III. Patients in the melanoma group had a significantly more frequently outdoor or partially outdoor occupations and had 3 or more sunburns during early life. Of note, the number of sunny holidays was higher in the control group. Use of sun beds was low in both groups, but significantly lower in the melanoma group. Males, individuals over 45 years of age, with low educational level and those with familial history of melanoma were less likely to use sun beds in both groups $(\mathrm{P}<0.01)$.

Self-reported protective behaviour. Self-reported protective behaviors are presented in Table IV. There was no difference between the groups (\%) regarding use of sunscreens; females, young individuals and those with a higher level of education were more likely to use sunscreens in both groups $(\mathrm{P}>0.01)$. Those previously diagnosed with melanoma were more likely to check their skin for moles, especially at short intervals of time, and to see a doctor for mole examination in the previous year $(\mathrm{P}<0.01)$.

Attitude towards a new or changing mole. Attitude towards a new or changing mole of the study population is reported 
Table II. Self-reported melanoma risk factors.

\begin{tabular}{|c|c|c|c|}
\hline Variables & $\begin{array}{c}\text { Control } \\
(\mathrm{n}, \%)\end{array}$ & $\begin{array}{c}\text { Melanoma } \\
(\mathrm{n}, \%)\end{array}$ & P-value \\
\hline \multicolumn{4}{|c|}{ What happens to your skin in the sun? } \\
\hline Never tans & $19(2.0)$ & $14(5.7)$ & \multirow[t]{4}{*}{$<0.01$} \\
\hline Tans with difficulty & $203(21.2)$ & $82(33.3)$ & \\
\hline Tans easily & $420(43.9)$ & $92(37.4)$ & \\
\hline Tans always & $314(32.8)$ & $58(23.6)$ & \\
\hline \multicolumn{4}{|l|}{ Does your skin freckle? } \\
\hline No & $647(67.7)$ & $112(45.3)$ & \multirow[t]{2}{*}{$<0.01$} \\
\hline Yes & $309(32.3)$ & $135(54.7)$ & \\
\hline \multicolumn{4}{|c|}{ How many moles do you have? } \\
\hline None & $172(18.0)$ & $21(8.5)$ & \multirow[t]{3}{*}{$<0.01$} \\
\hline Less than 20 & $596(62.3)$ & $116(47)$ & \\
\hline More than 20 & $188(19.7)$ & $110(44.5)$ & \\
\hline \multicolumn{4}{|c|}{ Do you have moles with irregular edge and colour? } \\
\hline No & $795(83.2)$ & $117(49)$ & \multirow[t]{2}{*}{$<0.01$} \\
\hline Yes & $161(16.8)$ & $122(51)$ & \\
\hline \multicolumn{4}{|c|}{ What is your natural hair colour? } \\
\hline Fair & $81(8.5)$ & $33(13.4)$ & \multirow[t]{4}{*}{$<0.01$} \\
\hline Red & $18(1.9)$ & $4(1.6)$ & \\
\hline Brown & $624(65.3)$ & $181(73.6)$ & \\
\hline Black & $233(24.4)$ & $28(11.4)$ & \\
\hline
\end{tabular}

in Table V. Compared with controls, those who were previously diagnosed with melanoma were more likely to visit a dermatologist on noticing a new mole $(\mathrm{P}<0.01)$. Subjects were more likely to check for moles, if they were females or over 45 years of age. There were no differences regarding how quickly a new mole should be checked between the groups.

In the melanoma group, the time interval between noticing the tumour and first presentation to the doctor ranged from 0 to 360 weeks, with a median of 24 weeks (data not shown).

\section{Discussion}

The present study was conducted to document and compare melanoma risk factors and skin health behaviour in patients diagnosed with melanoma and people not affected by this disease in a large medical university centre from Romania (Cluj-Napoca). To the best of our knowledge, this the first such study performed in this country. The relevance of the studied problem is given by the later diagnosis of advanced stage melanoma in Central and Eastern Europe compared with other parts of Europe and the need to gather data for future primary and secondary preventive campaigns (3).

There are several important findings from this study. As expected, those who have had cutaneous melanoma have a higher number of risk factors compared with those without a positive history. Consistent with findings from other studies, fair skin, tendency to develop freckles and a nevus-prone phenotype are risk factors for melanoma in the studied population (12).

Regarding sun exposure, those previously diagnosed with melanoma were more frequently involved in outdoor or partially outdoor professional activities, and had at least 1-2 sunburns, more frequently 3 or more sunburns in their early life, compared with controls. Evidence for a causal role of occupational sun exposure in melanoma is equivocal (13). An increased risk has been found in some studies, but a negative association was documented in others (13). Our study shows a higher risk of melanoma in those having an outdoor or partially outdoor profession. It has been suggested that occupational exposure tends to increase the risk of melanoma on usually exposed sun sites, especially at low latitudes, but we did not explore this hypothesis in our study (13). Regarding sunburns, our findings are similar with those from the literature showing an increased risk of melanoma with an increasing number of sunburns (14).

Our study shows a relatively low proportion of persons using sun beds in the control group (16.1\%), a much lower percentage compared with that reported in a recent metaanalysis including 16 countries (35.7\%), but concordant with that reported by the EDIFICE Melanoma-survey $(15,16)$. In our population, young females with a high educational level were more likely to use sun beds. Those who were previously diagnosed with melanoma reported use of sun beds in a much lower proportion than controls. Most of the participants in the control group $(76 \%)$ have had more than one sunny holiday in the last five years, compared with those diagnosed with melanoma; $48.6 \%$ of the last reported not having a sunny holiday in the previous 5 years. One possible explanation for the very low percentage of sun bed use and low number of sunny vacations in the melanoma group is that the diagnosis of melanoma led to a significant decrease in risk behaviour. Overall, the results 
Table III. Self-reported risk behaviour in the study population.

\begin{tabular}{|c|c|c|c|}
\hline Variables & $\begin{array}{l}\text { Control } \\
(\mathrm{n}, \%)\end{array}$ & $\begin{array}{c}\text { Melanoma } \\
(\mathrm{n}, \%)\end{array}$ & P-value \\
\hline \multicolumn{4}{|c|}{ Occupation (professional sun exposure) } \\
\hline Outdoor & $44(4.6)$ & $42(17.3)$ & \multirow[t]{3}{*}{$<0.01$} \\
\hline Partially outdoor & $201(21)$ & $77(31.7)$ & \\
\hline Indoor & $711(74.4)$ & $124(51.0)$ & \\
\hline \multicolumn{4}{|c|}{ Do you use sun beds? } \\
\hline No & $802(83.9)$ & $241(98.0)$ & \multirow[t]{5}{*}{$<0.01$} \\
\hline Very rarely & $136(14.2)$ & $5(2)$ & \\
\hline Monthly & $14(1.5)$ & $0(0)$ & \\
\hline Weekly & $3(0.3)$ & $0(0)$ & \\
\hline More frequently & $1(0.1)$ & $0(0)$ & \\
\hline \multicolumn{4}{|c|}{ How many sunny holidays did you have in the last 5 years? } \\
\hline None & $229(24)$ & $119(48.6)$ & \multirow[t]{4}{*}{$<0.01$} \\
\hline $1-2$ & $352(36.8)$ & $59(24.1)$ & \\
\hline $3-4$ & $218(22.8)$ & $37(15.1)$ & \\
\hline 5 or more & $157(16.4)$ & $30(12.2)$ & \\
\hline \multicolumn{4}{|c|}{ How many times have you had sunburns in your early life? } \\
\hline Never & $363(38)$ & $59(23.9)$ & \multirow[t]{3}{*}{$<0.01$} \\
\hline $1-2$ & $399(41.7)$ & $68(27.5)$ & \\
\hline 3 or more & $194(20.3)$ & $120(48.6)$ & \\
\hline
\end{tabular}

Table IV. Self-reported protective behaviour in the study population.

\begin{tabular}{|c|c|c|c|}
\hline Variables & $\begin{array}{c}\text { Control } \\
(\mathrm{n}, \%)\end{array}$ & $\begin{array}{c}\text { Melanoma } \\
(\mathrm{n}, \%)\end{array}$ & P-value \\
\hline \multicolumn{4}{|c|}{ Do you use sun protection creams? } \\
\hline Yes & $556(58.2)$ & $135(54.9)$ & $>0.01$ \\
\hline \multicolumn{4}{|c|}{ Do you check your skin for moles? } \\
\hline Yes & $544(56.9)$ & $189(76.5)$ & $<0.01$ \\
\hline \multicolumn{4}{|c|}{ If yes, how often? } \\
\hline Monthly & $215(39.5)$ & $130(68.4)$ & $<0.01$ \\
\hline Yearly & $127(23.3)$ & $25(13.2)$ & \\
\hline More rarely & $202(37.1)$ & $35(18.4)$ & \\
\hline \multicolumn{4}{|c|}{ Have you never seen your doctor for mole examination in the last year? } \\
\hline Yes & $132(13.8)$ & $65(26.4)$ & $<0.01$ \\
\hline
\end{tabular}

of the present study suggest that in our population exposure to natural sunlight is more important as risk factor for melanoma, compared with artificial UV exposure.

Use of sunscreens was reported by more than half of the participants and we found no differences between the groups. Young females with a high educational level were more likely to use sunscreens. Despite having comparable percentages in relation to other studies conducted in Europe $(9,17,18)$ we consider that the use of sunscreens in our population is low, demonstrating the need for health promotion messages on the use of sunscreen. Moreover, we found no differences between participants, so, contrary to other studies, the diagnosis of melanoma did not lead to an increase in sunscreen use in our population.

Self-skin examination was reported by approximately half of the participants in the control group but only one third performed it on a regular basis $(22.48 \%$ monthly and $13.28 \%$ yearly). In contrast, more than $75 \%$ of those diagnosed with melanoma reported self-skin examination, most of them fulfilling it monthly (data not shown). Our study established that sex, age and high educational level are promoting factors for self-skin examination, consistent with the findings from other studies $(20,21)$. Recommendation for the frequency of self-examination are not unified, however, most authors 
Table V. Attitude towards a new or changing mole.

\begin{tabular}{lcc}
\hline Variables & $\begin{array}{c}\text { Conrol } \\
(\mathrm{n}, \%)\end{array}$ & $\begin{array}{c}\text { Melanoma } \\
(\mathrm{n}, \%)\end{array}$ \\
\hline What do you do on noticing a new or a changing mole? & $246(25.7)$ & $42(17.4)$ \\
Visit my GP & $277(29)$ & $142(58.9)$ \\
Visit a dermatologist & $96(10)$ & $14(5.8)$ \\
Ask a friend/partner to check it & $337(35.3)$ & $43(17.8)$ \\
Ignore it & & $165(68.5)$ \\
How quickly should a new mole be checked? & $598(62.6)$ & $19(7.9)$ \\
In the first month & $82(8.6)$ & $21(8.7)$ \\
In the first 2 months & $59(6.2)$ & $33(13.7)$ \\
In the first 3 months & $191(20)$ & $3(1.2)$ \\
Eventually & $26(2.7)$ & $>0.01$ \\
Never &
\end{tabular}

recommend its monthly conducting (19). Studies examining the frequency of skin self-examination show that between 23 and $61 \%$ of individuals in the general population report engaging in skin self-examination at least annually with higher rates in Australia and the United States, and higher rates in those with a familial or personal history of melanoma $(20,21)$. Studies show that one-third of women and men with no history of melanoma had never engaged in self-skin examination, compared to approximately $4 \%$ of participants with a personal history of disease (21). The percentage of participants who had never engaged in skin self-examination observed in our study ( $23.5 \%$ in the melanoma group and $43.1 \%$ in controls) is higher than reported in previous studies $(20,21)$, representing a matter of concern which should be addressed in future campaigns. The reported clinical skin examination performed by a doctor in the previous year is very low in our study, being declared by only 26.4 and $13.8 \%$ respectively of the participants in the melanoma and control group. The proportion in the general population is in the range reported by other studies, but the one reported by those with a previous diagnosis of melanoma is much lower $(20,21)$. Our opinion is that the general population and especially patients already diagnosed with melanoma should be made aware of the importance of self-skin examination, clinical and dermoscopic examination, in particular in those with multiple nevi $(22,23)$.

The most concerning finding of our study is that in the presence of a new or changing mole $17.8 \%$ of the participants in the melanoma group would ignore the lesion and only $76.3 \%$ would visit a doctor, although $85.1 \%$ of them considered that such a lesion should be checked in the first three months. The results were even more concerning in the general population, with much lower percentages than that recently reported by EDIFICE Melanoma survey and could be one of the explanations for the later diagnosis of advanced stage melanoma (16). Moreover, our findings support the idea derived from other studies, that knowledge about melanoma and protective behaviours is not consistently associated with the implementation of those behaviours (9).

In the melanoma group, the time interval between noticing the lesion and first presentation varied between 0-360 weeks, with a mean of 24 weeks, which is considered a long interval. Melanoma is one of the cancers in which an increased time to diagnosis is significantly associated with a poorer prognosis, so this is an important matter which should be addressed in preventive campaigns (24).

Our study has a few limitations. Firstly, answers for behaviour were self-reported and not based on direct observation, which may potentially influence the accuracy of the responses. Secondly, there was a gap between data collection in the control group and the melanoma group, so our results could have been affected by public education campaigns. As strength, this evaluation provided so far missing material regarding melanoma risk factors and skin health behaviour in our country.

Because of melanoma aggressiveness, a lot of effort is made in order to understand the pathogenesis, risk factors, prognostic factors and best therapeutic approach in melanoma patients (25-27). So far, primary and secondary prevention coupled with early diagnosis and treatment seems to be the best options.

In conclusion, this is the first study that offers insight into melanoma risk factors and sun-related behaviours in the Romanian population. Our study suggests that in our population exposure to natural sunlight is more important as risk factor for melanoma, compared with artificial UV exposure. The low self and clinical skin-examination together with the relatively low percentage of participants which would consult a doctor in case of new/changing mole could be one of the explanations for the late diagnosis of melanoma in the studied population. Although our data suggest that melanoma patients are better educated about how to avoid a second primary melanoma, our results are concerning when compared with studies from other countries. Overall, the results of the present survey demonstrate, the urgent need for population health campaigns regarding not only primary but also secondary melanoma prevention.

\section{Acknowledgements}

Not applicable. 


\section{Funding}

This manuscript was partially supported by grants of the Ministry of Research and Innovation (UEFISCDI), PN-III-P1-1.2-PCCDI-2017-0341.

\section{Availability of data and materials}

The datasets used and/or analyzed during the current study are available from the corresponding author on reasonable request.

\section{Authors' contributions}

OF, LU, SS, SD, AV, DV, EC, SCV and RC were responsible for research creation and design, data acquisition, analysis and interpretation of data, statistical analysis, manuscript drafting, and critical revision of the manuscript for important intellectual content. All authors read and approved the final version of manuscript.

\section{Ethics approval and consent to participate}

This study was approved by the Ethics Committee of the 'Iuliu Hatieganu' University of Medicine and Pharmacy (Cluj-Napoca, Romania). All the participants gave their written consent to be included in this study.

\section{Patient consent for publication}

Not applicable.

\section{Competing interests}

The authors declare that they have no competing interests.

\section{References}

1. Jemal A, Bray F, Center MM, Ferlay J, Ward E and Forman D: Global cancer statistics. CA Cancer J Clin 61: 69-90, 2011.

2. Touboul C: Methodology of the EDIFICE Melanoma survey. J Eur Acad Dermatol Venereol 29 (Suppl 2): 2-5, 2015.

3. Forsea AM, Del Marmol V, de Vries E, Bailey EE and Geller AC: Melanoma incidence and mortality in Europe: New estimates, persistent disparities. Br J Dermatol 167: 1124-1130, 2012.

4. Murchie P and Iweuke FC: Comparing personal risk, melanoma knowledge and protective behaviour in people with and without melanoma: A postal survey to explore educational needs in northeast Scotland. J Cancer Educ 26: 341-347, 2011.

5. Butler DP, Lloyd-Lavery A, Archer CM and Turner R: Awareness of and attitudes towards skin-cancer prevention: A survey of patients in the UK presenting to their general practice. Clin Exp Dermatol 38: 338-343, 2013.

6. Diffey BL and Norridge Z: Reported sun exposure, attitudes to sun protection and perceptions of skin cancer risk: A survey of visitors to Cancer Research UK's SunSmart campaign website. Br J Dermatol 160: 1292-1298, 2009.

7. Devos SA, Baeyens K and Van Hecke L: Sunscreen use and skin protection behavior on the Belgian beach. Int J Dermatol 42: 352-356, 2003

8. Gambichler T, Dissel M, Altmeyer P and Rotterdam S: Evaluation of sun awareness with an emphasis on ultraviolet protection by clothing: A survey of adults in Western Germany. J Eur Acad Dermatol Venereol 24: 155-162, 2010.

9. Gavin A, Boyle R, Donnelly D, Donnelly C, Gordon S, McElwee G and O'Hagan A: Trends in skin cancer knowledge, sun protection practices and behaviours in the Northern Ireland population. Eur J Public Health 22: 408-412, 2012.
10. Haluza D and Cervinka R: Perceived relevance of educative information on public (skin) health: A cross-sectional questionnaire survey. J Prev Med Public Health 46: 82-88, 2013.

11. Ungureanu L, Senilă S, Vornicescu D, Vesa SC, Ionuț R and Cosgarea R: Melanoma knowledge, risk factors awareness and skin health behaviours: A populational-based study in Central Romania. J Eur Acad Dermatol Venereol 30: e213-e215, 2016.

12. Caini S, Gandini S, Sera F, Raimondi S, Fargnoli MC, Boniol M and Armstrong BK: Meta-analysis of risk factors for cutaneous melanoma according to anatomical site and clinico-pathological variant. Eur J Cancer 45: 3054-3063, 2009.

13. Rushton L and J Hutchings S: The burden of occupationally-related cutaneous malignant melanoma in Britain due to solar radiation. Br J Cancer 116: 536-539, 2017.

14. Dennis LK, Vanbeek MJ, Beane Freeman LE, Smith BJ, Dawson DV and Coughlin JA: Sunburns and risk of cutaneous melanoma: Does age matter? A comprehensive meta-analysis. Ann Epidemiol 18: 614-627, 2008.

15. Wehner MR, Chren MM, Nameth D, Choudhry A, Gaskins M, Nead KT, Boscardin WJ and Linos E: International prevalence of indoor tanning: A systematic review and meta-analysis. JAMA Dermatol 150: 390-400, 2014.

16. Grange F, Mortier L, Crine A, Robert C, Sassolas B, Lebbe C, Lhomel C and Saiag P: Prevalence of sunbed use, and characteristics and knowledge of sunbed users: Results from the French population-based Edifice Melanoma survey. J Eur Acad Dermatol Venereol 29 (Suppl 2): 23-30, 2015.

17. Mortier L, Lepesant P, Saiag P, Robert C, Sassolas B, Grange F, Lhomel $C$ and Lebbe C: Comparison of sun protection modalities in parents and children. J Eur Acad Dermatol Venereol 29 (Suppl 2): 16-19, 2015.

18. Bertolin M, Cercatto MC, Requena C, Serra-Guillen C, Llombart B, Sanmartin O, Guillen C and Nagore E: Awareness, attitude, and adherence to preventive measures in patients at high risk of melanoma. A Cross-Sectional study on 185 patients. J Cancer Educ 30: 552-566, 2015.

19. Goodson AG and Grossman D: Strategies for early melanoma detection: Approaches to the patient with nevi. J Am Acad Dermatol 60: 719-738, 2009.

20. Kasparian NA, McLoone JK and Meiser B: Skin cancer-related prevention and screening behaviors: A review of the literature. J Behav Med 32: 406-428, 2009.

21. Kasparian NA, Bränström R, Chang YM, Affleck P, Aspinwall LG, Tibben A, Azizi E, Baron-Epel O, Battistuzzi L, Bruno W, et al; Melanoma Genetics Consortium (GenoMEL): Skin examination behavior: The role of melanoma history, skin type, psychosocial factors, and region of residence in determining clinical and self-conducted skin examination. Arch Dermatol 148: 1142-1151, 2012.

22. Rotaru M, Nati AE, Avrămoiu I, Grosu F and Mălăescu GD: Digital dermoscopic follow-up of 1544 melanocytic nevi. Rom J Morphol Embryol 56: 1467-1472, 2015.

23. Ungureanu L, Senilă S, Dănescu S, Vesa SC and Cosgarea R: Patient compliance: The main drawback in the dermoscopic follow-up of melanocytic lesions. J Eur Acad Dermatol Venereol 30: 457-458, 2016.

24. Neal RD, Tharmanathan P, France B, Din NU, Cotton S, Fallon-Ferguson J, Hamilton W, Hendry A, Hendry M, Lewis R, et al: Is increased time to diagnosis and treatment in symptomatic cancer associated with poorer outcomes? Systematic review. Br J Cancer 112 (Suppl 1): S92-S107, 2015.

25. Neagu M, Caruntu C, Constantin C, Boda D, Zurac S, Spandidos DA and Tsatsakis AM: Chemically induced skin carcinogenesis: Updates in experimental models (Review). Oncol Rep 35: 2516-2528, 2016.

26. Zurac S, Neagu M, Constantin C, Cioplea M, Nedelcu R, Bastian A, Popp C, Nichita L, Andrei R, Tebeica T, et al: Variations in the expression of TIMP1, TIMP2 and TIMP3 in cutaneous melanoma with regression and their possible function as prognostic predictors. Oncol Lett 11: 3354-3360, 2016.

27. Caruntu C, Boda D, Constantin C, Caruntu A and Neagu M: Catecholamines increase in vitro proliferation of murine B16F10 melanoma cells. Acta Endocrinol (Copenh) 10: 545-558, 2014.

(i) $($ ) This work is licensed under a Creative Commons Attribution-NonCommercial-NoDerivatives 4.0 International (CC BY-NC-ND 4.0) License. 